\title{
DISCRETE MOMENT PROBLEMS WITH DISTRIBUTIONS KNOWN TO BE UNIMODAL
}

\author{
ERSOY Subasi, Mine SubASI AND ANDRÁS PRÉKOPA
}

\begin{abstract}
Discrete moment problems with given finite supports and unimodal distributions with known mode, are formulated and used to obtain sharp lower and upper bounds for expectations of higher order convex functions of discrete random variables as well as probabilities of the union of events. The bounds are based on the knowledge of some of the power moments of the random variables involved, or the binomial moments of the number of events which occur. The bounding problems are formulated as LP's and dual feasible basis structure theorems as well as the application of the dual method of linear programming provide us with the results. Applications in PERT and reliability are presented.
\end{abstract}

Mathematics subject classification (2000): 60E15, 90B15, 90B25, 90C05.

unimodality.

Keywords and phrases: Discrete moment problem, linear programming, bounding probabilities, discrete

\section{REFERENCES}

[1] J. BATtERSBy, Network Analysis for Planning and Scheduling, Third Ed., Macmillan, 1970.

[2] E. Boros, A. PRÉKOPA, Closed form two-sided bounds for probabilities that exactly $r$ and at least $r$ out of $n$ events occur, Math. Oper. Res., 14, (1989), 317-347.

[3] J. BUKSZÁR, A. PRÉKOPA, Probability bounds with cherry trees, Math. Oper. Res., 26, (2001), 174-192.

[4] J. BuKszÁr, Hypermultitrees and Bonferroni Inequalities, Math. Ineq. and Applications, 6, (2003), 727-745.

[5] D.A. Dawson, A. SAnKofF, An inequality for probabilities, Proceedings of the American Mathematical Society, 18, (1967), 504-507.

[6] M. FeKETE, G. PóLYA, Überein ein Problem von Laguerre, Rediconti del Circolo Matematico di Palermo, 23, (1912), 89-120.

[7] M. FrÉCHET, Les Probabilités Associées a un Systéme d'Événement Compatibles et Dépendants, Actualités Scientifique et Industrielles, Nos. 859, 942, (1940/43), Paris.

[8] J. Galambos AND I. Simonelli, Bonferroni-type inequalities with applications, Springer, Wahrscheinlichkeits, 1996.

[9] D. HunTER, Bounds for the probability of a union, Journal of Applied Probability, 13, (1976), 597-603.

[10] C. Jordan, Calculus of Finite Differences, Chelsea, New York, 1947.

[11] S.M. KWEREL, Most Stringent bounds on aggregated probabilities of partially specified dependent probability systems, J. Amer. Stat. Assoc., 70, (1975), 472-479.

[12] B.B. MANDELBROT, The fractal geometry of nature, Freeman, New York, 1977.

[13] A. PRÉKOPA, Boole-Bonferroni inequalities and linear programming, Oper. Res., 36, (1988), 145-162.

[14] A. PRÉKOPA, Totally positive linear programming problems, L.V. Kantorovich Memorial Volume, Oxford Univ. Press, New York, (1989), 197-207.

[15] A. PRÉKOPA, Sharp bounds on probabilities using linear programming, Oper. Res., 38, (1990), 227-239.

[16] A. PRÉKOPA, The discrete moment problem and linear programming, Discrete Applied Mathematics, 27, (1990), 235-254.

[17] A. PRÉKOPA, Stochastic Programming, Kluwer Academic Publishers, Dordtecht, Boston, 1995.

[18] A. PRÉKOPA, A brief introduction to linear programming, Math. Scientist, 21, (1996), 85-111.

[19] A. PRÉKOPA, Discrete higher order convex functions and their applications, in: N. Hadjisavvas, J.E. Martinez-Legaz, J-P. Penot (Eds.), Generalized Convexity and Monotonicity, Lecture Notes in Economics and Mathematical Systems, Springer, (2001), 21-47. 
[20] A. PRÉKOPA, J. LONG AND T. SZÁNTAI, New bounds and approximations for the probability distribution of the length of critical path, in: K. Marti, Yu. Ermoliev, G. Pflug (Eds.), Dynamic Stochastic Optimization, Lecture Notes in Economics and Mathematical Systems 532, Springer, Berlin, Heidelberg, (2004), 293-320. 